\title{
ANALYSIS OF ALTERNATIVE COLLABORATIVE ROUTE SELECTION STRATEGIES BASED ON COST AND THROUGHPUT
}

\author{
Bojia YE ${ }^{1}$, Lance Sherry (Ph.D) ${ }^{2}$, Minghua Hu ${ }^{1}$, Chun-Hung Chen (Ph.D $)^{2}$ \\ 1 College of Civil Aviation, Nanjing University of Aeronautics and Astronautics, Nanjing, China \\ 2 Center for Air Transportation Systems Research, Dept. of Systems Engineering \& Operations \\ Research,George Mason University, Fairfax, VA
}

\begin{abstract}
Air Traffic Flow Management (TFM) is a collaborative process between the airspace provider (ATCSCC) and the airspace users (AOCs). The result of the collaboration should be an outcome that maximizes the utility of the system without excessively penalizing any of the agents. This paper describes the results of a tradeoff analysis between flight costs and sector throughput for combinations of ATCSCC and AOC strategies for flight-plan route selections in the presence of weather that affects enroute airspace capacity. The analysis is conducted using a discrete event simulation model of an airspace network with several airports, sectors and alternative airways. The results of the analysis indicate that when both Miles-in-Trails (MIT) restrictions for the airspace, as well as, TFM rerouting in collaboration with the AOC takes place, the performance of the overall system achieves a reduction of $67 \%$ in delay costs, $61 \%$ in delay time, $22 \%$ in delay rate and $69 \%$ in total passengers delay time (compared to the baseline). The implications of the results are discussed in this paper.
\end{abstract}

\section{Introduction}

Air Traffic Flow Management (TFM) is a collaborative process between air traffic management authority (e.g. ATCSCC) and the airspace users (e.g. AOCs). The current TFM system limits the degree of collaboration that can occur in air traffic flow management [1]: ATCSCC and AOC do not have shared impact assessment tools, and therefore make decisions based on divergent predictions of airspace availability. ATCSCC generally does not know the specific concerns of the airlines, and have to make routing decisions without regard to airline preferences. The bulk of the problem solving responsibility falls upon the ATCSCC (i.e. Ground Delay and Airspace Flow Programs) and the
ARTCCs (Miles-in-Trail), increasing the already high workload [2].

The Next Generation Air Transportation System (NextGen) concept-of-operations emphasizes increased information sharing, communication, and sharing responsibility to solve problems between the Air Navigation Service Provider and the airlines. FAA describes a new method Collaborative Trajectory Options Program (CTOP) which provides the NAS users their most preferred trajectory [3].

Research is being done using simulation to solve the en route congestion problem, and some mature real-time tools have already been developed [4] [5]. Wanke et al. [6] described a concept for managing en route congestion in the presence of uncertainty. As a result flight-specific maneuvers were generated to reduce the congestion risk. Ramamoorthy et al. [7] used a trajectory-based probabilistic TFM approach by delaying or rerouting flights in order of calculated congestion cost, to maximize the congestion reduction per TFM initiative. For both of the tools, the probabilistic demand and capacity models reflect the uncertainty in the daily operations and are the key factors that determine the outcome. Recently, some agent-based simulations are used to solve the Collaborative Traffic Flow Management (CTFM) problem. Wolfe et al. [2] built an initial agent-based simulation of CTFM with Brahms where static route capacity and flight schedules with agent strategies are used throughout the simulation. Calderon-Meza et al. [8] studied the effects on the NAS of adaptable route selection behavior of airlines based on current and historical performance information by using Future ATM Concepts Evaluation Tool (FACET).

This paper describes a discrete event simulation model, using Arena [9], to evaluate the alternative route selection strategies based on flight cost and sector throughput. First, a simulated airspace network with several airports, sectors and flight flow is constructed. Next, a weather event which can cause capacity-reducing for the target sector is created. 
Then two kinds of agents representing ATCSCC and AOCs are simulated to make decisions based on their own individual objectives. The results of the analysis are: the performance of the overall system achieves a $67 \%$ reduction in delay costs, $61 \%$ in delay time, $22 \%$ in delay rate and $69 \%$ in total passengers delay time (compared to the baseline).

The paper is organized as follows: Section II describes the models and strategies, Section III introduces the approach and the details of Arena model, Section IV provides the results of the experiments and some comparisons and Section V provides general conclusions based on the results.

\section{Model Description}

The overall model is illustrated in figure 1. It includes origin and destination airports, flight routes and airspace sectors. Relevant metric and strategies are described in Agents strategies definition. To simulate the strategies made by AOCs and ATCSCC agents, two models for estimating flight delay and cost are built in estimated flight delay and cost model.

\section{Airspace Network Definition}

\section{Airspace Structure}

A network comprising two types of aggregate airports and seven sectors is established first. The aggregate airports $\mathrm{A}$ and $\mathrm{C}$ represent the airports from which the flights will depart, and the aggregate airports $\mathrm{B}$ and $\mathrm{D}$ are the destinations. In the real world, the aggregate airports are described as several different airports that are not necessarily collocated but include some flights scheduled to travel though a common route segment. The combination of sectors represents a route segment in which a flight may pass through according to the schedule. Then directional flows from the aggregate departure airports to the aggregate destination airports are created. Each sector has a capacity limitation which is defined as the number of aircraft that can fly in the sector simultaneously in accordance with the current air traffic control rules (ATO Order JO 7110.65T, Air Traffic Control). Also each sector should have different transit times and several different entrance and exit points. In order to simplify the flying process, we propose that each sector has similar transit time.

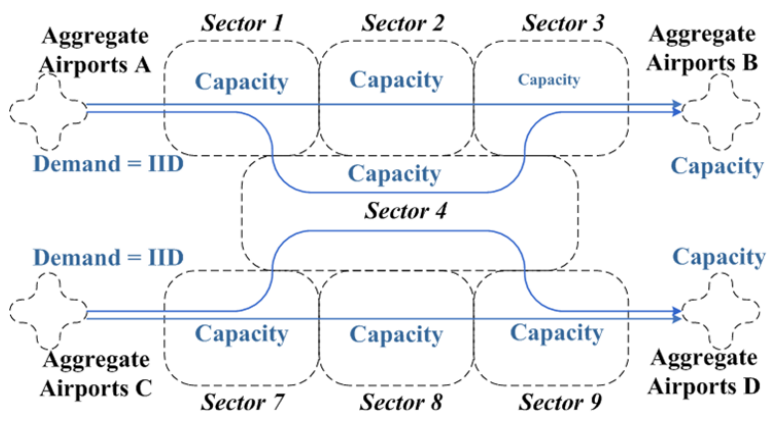

Figure 1. Airspace Structure

\section{Capacity Uncertainty}

Capacity uncertainty is a significant factor that affects the performance of air traffic system. Sources of capacity uncertainty include: 1) the difference in abilities of different air traffic controllers; 2) the uncertainties in wind forecasting and aircraft performance modeling; 3) different traffic flow patterns [6].

In the model, capacity uncertainty is defined by two parameters: 1) establish the sector transit time as normally distributed random variable that has an independent and identical distribution (IID); 2) add a capacity changing event which may be caused by severe weather or ATC problem. Each sector is initialized with a specific number of capacity resources. The classical queueing theory is used to simulate the aircraft flying through each sector. A flight which arrives and finds the capacity resources available enters the sector immediately and holds one capacity resource. A flight which arrives and finds the number of available capacity resources is zero joins the end of a single queue. Upon leaving this sector, a flight releases one capacity resource and then another flight can enter the sector in a first-come first-served (FCFS) order. When severe weather happens, some flight-levels and some entrances or exits in the sector may be blocked. In this situation, the number of capacity resources will be reduced for some time until the event ends. In this scenario, the bottleneck of the network can be simulated and also the dynamics and uncertainty of system can be captured.

\section{Demand Uncertainty}

Demand uncertainty is another problem in the current system performance. The pop-up traffic, changes in departure times and flight plans, cancellations, displacement of traffic, en route wind 
and ATC-caused deviations are the factors that may cause inaccurate prediction of demand. The demand uncertainty may lead to over- or underestimating the imbalance between demand and capacity.

The definition of the uncertainty characteristic of demand in the simulation system is very important. Inter-arrival times are created as IID random variables to model the randomness for pop-up traffic or flight cancellations. Thus a random flights' demand with known mean and variance are constructed. Since this paper proposes to measure the performance of the system and different strategic decisions, the probability distribution of demand will be an important input to the system.

In addition to the uncertainty of number of flights and departure time, other detailed information such as aircraft type, connecting/non-connecting flight is also created as IID random variables. The potential delay cost of each flight can be therefore be determined and included in the strategic decisions.

\section{Agents Strategies Definition}

\section{Relevant Metric for Different Agents}

To make decisions on the behalf of different agents, the goals of agents should be defined [2]. Besides the shared safety goal for both agents, the main objectives of ATCSCC Agent are: 1) congestion mitigation, 2) workload reduction, 3) airlines satisfaction. The main goals of AOC agents are: 1) cost reduction, 2) reliability guarantee and 3 ) on-time service.

In this paper, it is assumed that the goals are translated into metrics for each agent. A measure of congestion mitigation is described in terms of sector delay time and system delay time. Workload reduction is proposed as the number of capacity resources which will not appear in metric. Airlines satisfaction is thought to with the system delay cost and total passengers delay numbers. Reliability guarantee is about passengers delay number and total passengers delay time etc. On-time service links to time departure rate and delay rate. The metrics for the performance are defined in Table 1:

Table 1. System Performance Metric

\begin{tabular}{|l|l|l|}
\hline Metric & $\begin{array}{l}\text { Concerned } \\
\text { Agents }\end{array}$ & Objectives \\
\hline $\begin{array}{l}\text { On-Time } \\
\text { Departure }\end{array}$ & AOCs & on-time service \\
\hline
\end{tabular}

\begin{tabular}{|l|l|l|}
\hline Delay Rate & AOCS & on-time service \\
\hline $\begin{array}{l}\text { Sector } \\
\text { Delay Time }\end{array}$ & ATCSCC & congestion mitigation \\
\hline $\begin{array}{l}\text { Sector } \\
\text { Delay Cost }\end{array}$ & AOCs & cost reduction \\
\hline $\begin{array}{l}\text { System } \\
\text { Delay Time }\end{array}$ & ATCSCC & congestion mitigation \\
\hline $\begin{array}{l}\text { System } \\
\text { Delay Cost }\end{array}$ & $\begin{array}{l}\text { ATCSCC } \\
\text { AOCs }\end{array}$ & $\begin{array}{l}\text { airlines satisfaction } \\
\text { cost reduction }\end{array}$ \\
\hline $\begin{array}{l}\text { PAX Delay } \\
\text { Num }\end{array}$ & AOCs & reliability guarantee \\
\hline $\begin{array}{l}\text { Total PAX } \\
\text { Delay Time }\end{array}$ & $\begin{array}{l}\text { AOCs } \\
\text { ATCSCC }\end{array}$ & $\begin{array}{l}\text { reliability guaranteel } \\
\text { airlines satisfaction }\end{array}$ \\
\hline
\end{tabular}

\section{Different Kinds of Strategies}

Five alternative route selection strategies are introduced here in response to the capacity changing event. The following strategies represent the past, current and proposed TFM operations: 1) no intervention, 2) ARTCC introduces MIT, 3) AOCs introduce reroute decisions based pm ARTCC MIT, 4) ARTCC introduces MIT and Reroute, 5) ARTCC introduces MIT and Reroute based on ARTCC and AOCs decisions.

- No intervention occurs when no advance action is taken to respond to the capacity changing event. In this situation, the imbalance between demand and capacity in the capacity-reduced sector occurs and airborne delay strategies and FCFS rules are followed to deal with the congestion problem.

- ARTCC introduces a time-based Miles-InTrail (MIT) strategic decision based on advance planning. The initiative is designed to reduce the demand to match the capacity during the capacity reducing time. Subsequently, the airlines are required to take Ground Delay Program (GDP) to adjust the arrival time for the target sector. This strategy simulates the current TFM operation.

- AOCs introduce reroute decisions based on ARTCC MIT which is similar to the CTOP released by FAA. After the initial MIT decision is released by ARTCC, each AOC makes alternative route selections based on its own flight delay cost. The decision is the result of the estimated flight delay costs from the model which will be 
introduced later. Also, when the AOC decides to reroute affected flights instead of taking the GDP, the Compression Algorithm (CA) will be used to re-allocate the GDP time for the following flights.

- ARTCC introduces MIT and Reroute as a proposed strategy is similar to the current TFM operations. However, most of time decisions are made separately regarding GDP (caused by MIT) and Airspace Flow Program (AFP). In this strategy, GDP and AFP are used together to test the best performance of the system in a capacity changing event. Once ARTCCs make advance unilateral decision regarding MIT and rerouting of flights, the flights are rerouted randomly to adjust the imbalance in the target sector. Also, different percentages of rerouted flights are tested in this alternative to obtain the best system performance.

- ARTCC introduces MIT + Reroute based on ARTCC and AOCs is the final proposed strategy in this traffic flow management research. Unlike the reroute initiative given by TFM or AOCs unilaterally, we establish a procedure for ARTCC and AOCs to make collaborative decision about the reroute initiative. In this strategy, the MIT and percentage of rerouted flights will be decided by ARTCC first and then each AOC makes alternative route selection based on its own objectives, such as flight delay cost.

\section{Estimated Flight Delay and Cost Model}

\section{Estimated Flight Delay Model (EDM)}

This is a simplified flight delay estimation model used to calculate the potential delay time of each flight before its departure. Currently the result is based on the mean value of each sector transit time, the real time queue length of each sector and the potential GDP time for the target flight, AOCs use their own models easily in practice.

Since the sector transit time is set as IID, the mean value can be obtained easily. Also in practice, this value can be calculated from historical flight data by inductive-dynamic method. The real time queue length of each sector is a basic process variable which can be obtained from Arena model. This is research about demand prediction and the accuracy of the value is relative to the look-ahead times (LAT). This paper does not the research about prediction improvement. The assumption is that this value can be improved, acquired and shared by all NAS users in the NextGen or this value can be obtained by AOCs' own prediction model (e.g. model with historical data analysis and machine learning). The potential GDP time is based on the number of flights affected by MIT and it can be calculated based on the number of fights being held on the ground. Also, this information based on current ATFM operations. The estimated airborne delay time and estimated total delay time is shown in Equation (1) and (2). The estimated GDP delay time resulting from choosing route $j$ and extra delay time in sector $i$ for flight $f$ is included in Equation (3) and (4). The relative variables are defined in table 2 .

$$
\begin{aligned}
& T_{f, j}=T g_{f, j}+\sum_{i \in j}\left(T_{f, i}+D_{f, i}\right)-T S C H_{f} \\
& T a_{f, j}=\sum_{i \in j}\left(T_{f, i}+D_{f, i}\right)-T S C H_{f} \\
& T g_{f, j}=Q_{f, g} * T_{M I T} \\
& D_{f, i}=\left(Q_{f, i} / N_{i}\right) * T_{f, i}
\end{aligned}
$$

\begin{tabular}{|c|c|}
\hline Variables & Description \\
\hline$f$ & $\begin{array}{l}\text { A flight that is scheduled to fly } \\
\text { through the target route segment }\end{array}$ \\
\hline$j$ & $\begin{array}{l}\text { A flight route with the same entrance } \\
\text { and exit points but maybe different } \\
\text { transit sectors }\end{array}$ \\
\hline$i$ & $\begin{array}{l}\text { A segment of the flight route and it is } \\
\text { currently named by the sector it } \\
\text { belongs to }\end{array}$ \\
\hline$Q_{f, i}$ & $\begin{array}{l}\text { The length of flight queue in the sector } \\
\text { i before target flight joining the queue }\end{array}$ \\
\hline$Q_{f, g}$ & $\begin{array}{l}\text { The current length of flight queue in } \\
\text { the aggregate airports with GDP for } \\
\text { fight } f\end{array}$ \\
\hline$N_{i}$ & $\begin{array}{l}\text { Number of airspace resources for the } \\
\text { sector } i\end{array}$ \\
\hline$T_{f, i}$ & $\begin{array}{l}\text { Estimated transit time of the sector } i \\
\text { for flight } f \text { in the normal situation, the } \\
\text { mean value is used here }\end{array}$ \\
\hline $\mathrm{TSCH}_{f}$ & Scheduled route transit time from \\
\hline
\end{tabular}

Table 2. Variables for EDM 


\begin{tabular}{|l|l|}
\hline & flight planning for flight $f$ \\
\hline$T_{M I T}$ & $\begin{array}{l}\text { The MIT time initialized by ARTCC } \\
\text { for adjusting the imbalance in } \\
\text { potential congestion sector }\end{array}$ \\
\hline$D_{f, i}$ & $\begin{array}{l}\text { Estimated extra delay time in sector } i \\
\text { based on the length of flight queue } \\
\text { and sector transit time }\end{array}$ \\
\hline$T g_{f, j}$ & $\begin{array}{l}\text { Potential GDP time of flight f before } \\
\text { choosing route } j\end{array}$ \\
\hline$T a_{f, j}$ & $\begin{array}{l}\text { Estimated Airborne delay time of } \\
\text { flight } f \text { by choosing route j after } \\
\text { potential GDP }\end{array}$ \\
\hline$T_{f, j}$ & $\begin{array}{l}\text { Estimated total delay time of flight } f \\
\text { bychoose route jafter potential GDP }\end{array}$ \\
\hline
\end{tabular}

\section{Estimated Flight Delay Cost Model (ECM)}

This model is used to compute the estimated delay cost of each flight before its departure. First, it is assumes that the potential GDP time and estimated airborne delay time can be calculated by the EDM model. Then basic flight performance information is included to calculate the estimated flight delay cost. Four types of aircraft included in the simulation are Heavy, Large, Medium and Small. Aircraft have different number of seats and units time operating cost such as airborne fuel and crew delay cost. The estimated flight delay cost is computed by adding delay time fuel cost, passenger delay cost and crew delay cost together. It is assumed that the unit time of GDP fuel cost is $1 / 20$ of airborne delay fuel cost, and the unit time cost of a passenger on connecting flight is three times the cost of a passenger on nonconnecting flight. For connecting flight crew members, the crew delay cost also consider the potential passenger delay. The calculation of estimated flight delay cost is shown in Equation (5). Equation (6) reconciles the unit time passenger delay cost of a flight. The unit of time for passenger delay from the connecting flight is larger than nonconnecting flight. The relative variables are defined in table 3 .

$$
\begin{aligned}
& V p_{f}=F t_{f} *\left(3 * S_{f} * L d_{f} * U p+U c_{f}\right)+\left(1-F t_{f}\right) * S_{f} * L d_{f} * U p \\
& C_{f, j}=T a_{f, j} *\left(V p_{f}+V f_{f}\right)+T g_{f, j} *\left(V p_{f}+V f_{g}\right)
\end{aligned}
$$

Table 3. Variables for ECM

\begin{tabular}{|l|l|}
\hline Variables & Description \\
\hline$C_{f, j}$ & $\begin{array}{l}\text { Estimated total delay cost of flight } f \text { by } \\
\text { s route } j\end{array}$ \\
\hline
\end{tabular}

\begin{tabular}{|l|l|}
\hline$V p_{f}$ & $\begin{array}{l}\text { Unit time passenger delay cost in flight } \\
f, \text { include passenger and crew parts }\end{array}$ \\
\hline$V f_{f}$ & Unit time airborne fuel cost of flight $f$ \\
\hline$V f_{g}$ & Unit time GDP fuel cost of flight $f$ \\
\hline$F t_{f}$ & $\begin{array}{l}\text { Flight mission type of } f, 1 \text { represents } \\
\text { connecting flight }\end{array}$ \\
\hline$S_{f}$ & Seat number of flight $f$ \\
\hline$L d_{f}$ & Load factor of flight $f$ \\
\hline$U p$ & Unit time delay cost per passenger \\
\hline$U c_{f}$ & $\begin{array}{l}\text { Unit time delay cost of crew member in } \\
\text { flight } f\end{array}$ \\
\hline
\end{tabular}

\section{Methodology}

Arena software [9] is used here to simulate the airspace network and the five different alternative route selection strategies introduced above. Arena is an easy-to-use, powerful tool with flowchart-style modeling methodology, hierarchical modeling, and an extensive graphical library. The overall structure of our model is illustrated in Figure 2. The capacity changing event caused by severe weather is indicated in Figure3. The flights inter-arrival time and the transit time of each sector are initialized as normal distribution. Some key parameters for the experiments are in appendix I. In the model, each set of parameters is simulated by 100 flights over 100 times. The second strategy, ARTCC introduces a MIT strategic decision, used three different GDP times to find the most suitable MIT time. The fourth strategy, ARTCC introduces MIT and Reroute as a proposed strategy similar to the current TFM operations incorporated six different percentages of reroute flights to find optimum result. The fifth strategy applied six different percentages based on two different reroute rules to find the best solution. The results analysis is in the next section.

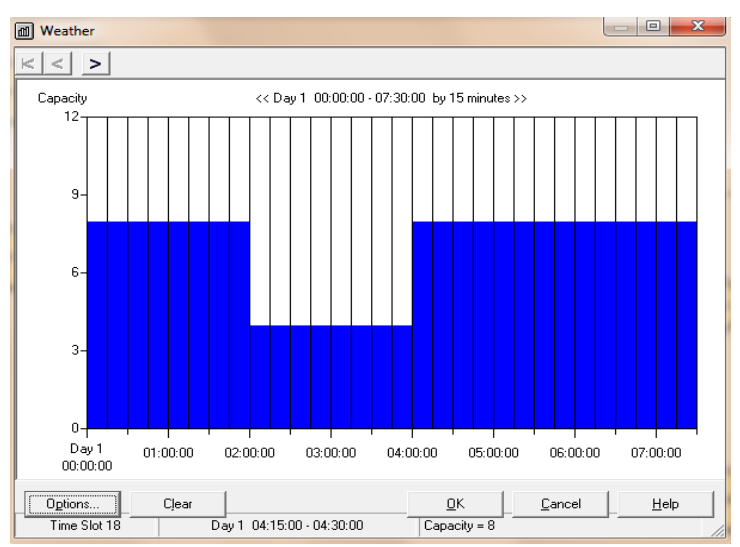

Fig. 3 Capacity Resources Changing Event 


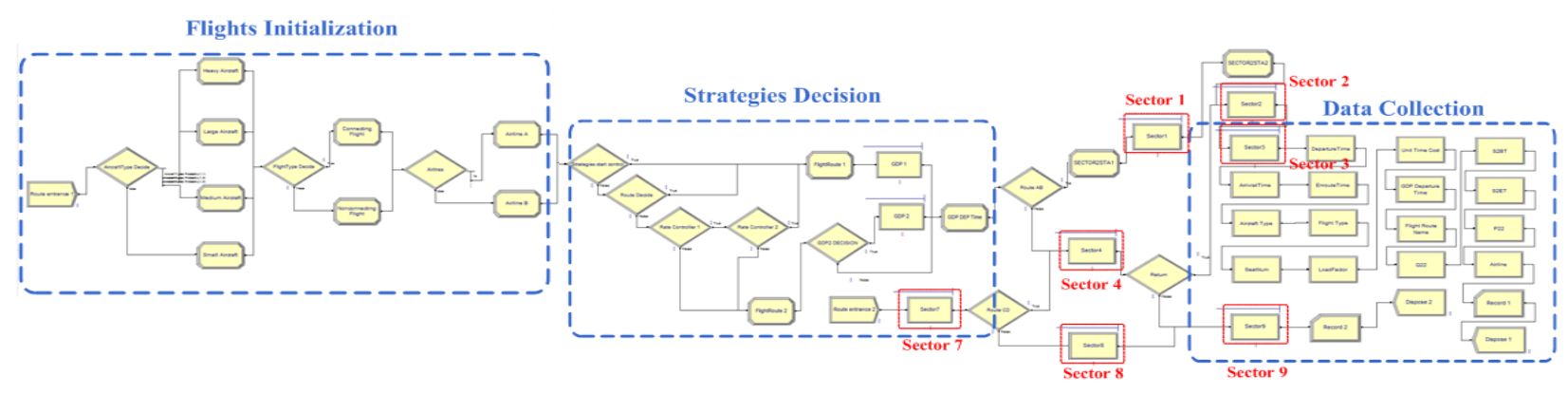

Fig. 2 Arena Simulation Model

\section{Results Analysis}

\section{No Intervention}

A baseline representation of the traffic summary in sector two with a no intervention strategy and a capacity changing event is illustrated in Figure 4. The red line represents the capacity resources by number of fights. The black curve shows the demand level of fights and the white line represents the number of airborne holding flights in the target sector. The dashed area denotes the number of specific capacity resources that are being used during the simulation time. The capacity resources and flight demand are functions of time of day. As shown in Figure 4, the specific capacity resources decreased from 8 to 4 between 120 minutes and 240 minutes for 2 hours. Also, based on the simulation results, this sector was the bottleneck of the airspace network during the reduced capacity time with 20.8 minutes average airborne delay time for each passed flight. The maximum number of simultaneous airborne delay flights for sector two is 21 and maximum airborne delay time is 60.6 minutes. This strategy may cause an increase in workload and a potential safety problem.

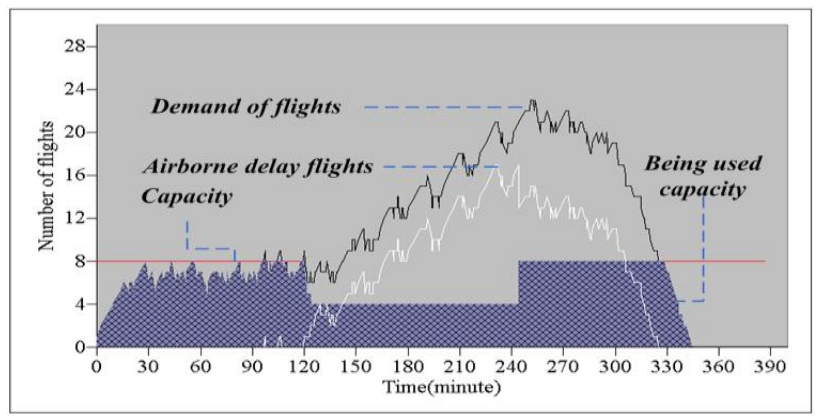

Fig. 4 No Intervention Strategy

\section{ARTCC Introduces MIT}

In the ARTCC introduces MIT strategy, the current TFM operation is simulated in which the demand matches the capacity-changing event. The MIT strategy begins at the start of reduced capacity resources and ends with capacity recovery. Subsequently, the airborne delayed flights affected by the MIT strategy will be further translated into GDP delay. After testing different MIT values (i.e. 4 to 6 minutes), the results indicate that, in the presence of uncertainty of operations, the maximum throughput with the lowest airborne delay and lowest total delay cost is achieved with a 5 minute MIT in the target sector as indicated in Figure 5. The number of simultaneous airborne delayed flights during the reduced capacity time in the 4 minute MIT strategy still increased to 8 while some capacity resources could not be used efficiently in the 6 minute MIT strategy.

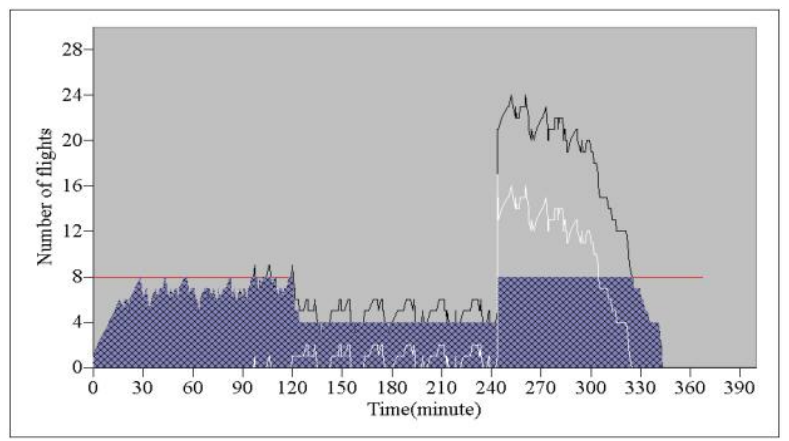

Fig. 5 ARTCC Introduces 5 Minutes MIT

Although the imbalance between demand and capacity may be alleviated during the reduced capacity time by the 5 minute MIT strategy and the average airborne delay time for each passed flight is reduced to 10.7 minutes, a "large spike" problem still 
results. The maximum number of simultaneous airborne delayed flights during the 5 minute time is as high as 22 and maximum airborne delay time is 52.6 minutes. In practice, the ARTCC may consider extending the MIT time, but this will not be considered here. Table 4 shows the metric values for the three different time MIT strategies. The results are the same from the system and sector perspectives. The 5 minute strategy is the best as it results in the minimum delay time and delay cost. Therefore, the 5 minute MIT strategy is selected as the best strategy introduced by ARTCC.

\section{Table 4. ARTCC Introduces MIT}

\begin{tabular}{|l|l|l|l|}
\hline $\begin{array}{l}\text { ARTCC } \\
\text { introduces MIT }\end{array}$ & $\begin{array}{l}4 \text { minutes minutes } \\
\text { MIT minutes }\end{array}$ & $\begin{array}{l}5 \text { MIT } \\
\text { MIT }\end{array}$ \\
\hline $\begin{array}{l}\text { Number of Fight } \\
\text { On-time } \\
\text { departure rate }\end{array}$ & 100.00 & 100.00 & 100.00 \\
\hline Delay rate & 0.59 & 0.63 & 0.63 \\
\hline $\begin{array}{l}\text { Sector Delay } \\
\text { time (minutes) }\end{array}$ & 2,232 & 2,051 & 2,566 \\
\hline $\begin{array}{l}\text { Sector Delay } \\
\text { cost (\$) }\end{array}$ & 806,733 & 738,696 & 919,975 \\
\hline $\begin{array}{l}\text { System Delay } \\
\text { Time (minutes) }\end{array}$ & 2,286 & 2,104 & 2,615 \\
\hline $\begin{array}{l}\text { System Delay } \\
\text { Cost (\$) }\end{array}$ & 826,888 & 758,069 & 937,759 \\
\hline $\begin{array}{l}\text { Number of } \\
\text { delayed PAX }\end{array}$ & 8,243 & 8,406 & 8,509 \\
\hline $\begin{array}{l}\text { Total PAX delay } \\
\text { time (minutes) }\end{array}$ & 319,956 & 306,803 & 385,042 \\
\hline
\end{tabular}

\section{AOCs Introduces Reroute Decisions Based on ARTCC MIT}

Based on the 5 minute MIT strategy introduced above, AOCs can further decide their most preferred trajectory in this strategy. In the experiment, each flight can obtain an estimated delay cost from the ECM model introduced in Section II. Also an alternative choice with less or no GDP time but longer route distance is available for each flight. The AOCs make dynamic decisions based on the calculated results. Since the GDP queue length changes with time and the available capacity resources for target sector is continuously updated, the decisions may change from flight to flight. The traffic situation of this strategy is illustrated in figure 6. The average airborne delay time for each passed flight is further reduced to 7.7 minutes. However, the "large spike" problem still exists with maximum 18 simultaneous airborne delayed flights and 44.2 minutes maximum airborne delay time.

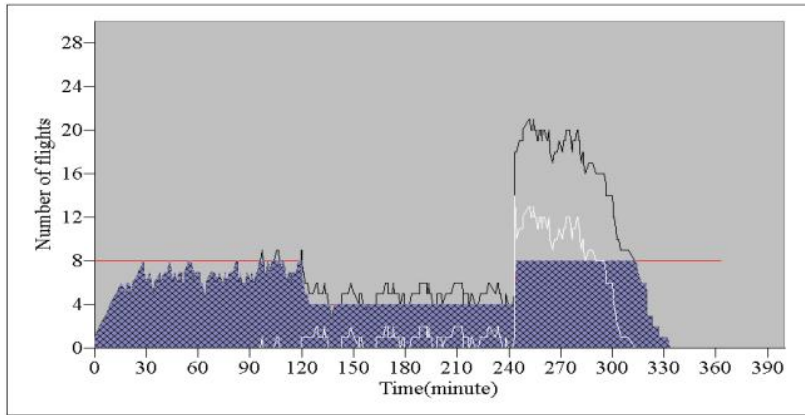

Fig. 6 Strategy from the Aspect of AOCs

\section{ARTCC Introduces MIT and Reroute}

In the strategy of ARTCC introduces MIT and Reroute, the 5 minute MIT strategy is used as primary initiative. On a trial basis, the percentage of reroute flights is changed from 10 to 60 percent with 10 percent step to find the best solution. The reroute flights are chosen randomly by the ARTCC. The strategy stops when capacity resources are recovered. The congestion problem can be solved efficiently with the minimum sector delay cost, system delay cost and total passenger delay cost when a 5 minute MIT with $40 \%$ flights rerouted initiative is taken and combined with a Compression Algorithm. The average airborne delay time for each passed flight is reduced to 0.7 minutes, the maximum simultaneous airborne delay flights reduced to 9 with 22 minutes maximum airborne delay time. The metric values for the different percentages of rerouted flights are displayed in Appendix II. The traffic situation is shown in Figure 7 and Figure 8 illustrates the tradeoff between delay cost and percentages of reroute flights.

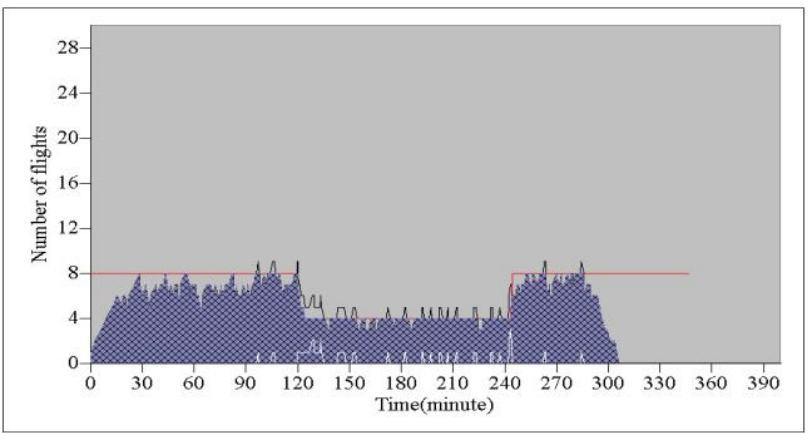

Fig. 7 ARTCC Introduces MIT and Reroute 


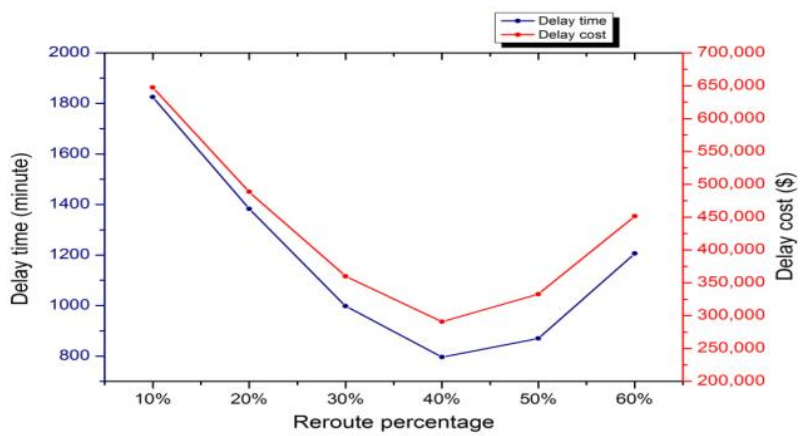

Fig. 8 Trade-off between Delay Cost and Reroute Percentage

\section{ARTCC Introduces MIT and Reroute based on ARTCC and AOCs}

In this strategy, a 5 minute MIT initiative with different percentages of rerouted flights is simulated here. The average airborne delay time for each passed flight is 0.18 minutes and the maximum number of simultaneous airborne delayed flights is 9 with 21.5 minutes maximum airborne delay time. The metric values for different percentages of rerouted flights in this strategy are contained in appendix III and IV. In looking at appendix III, it shows the selection based on Valuable-Flights Rerouted-First (VFRF) rules while appendix IV is based on Less-Valuable-Flights Rerouted-First (LFRF) rules. Although the VFRF performs better than LFRF when less than 30\% flights are rerouted, the minimum system delay time and cost can be achieved when $40 \%$ of flights are rerouted based on LFRF. Different environments may have different results, but the LFRF will be considered as the strategy representing ARTCC introducing MIT and Reroute based on ARTCC and AOC in this experiment. Figure 9 shows traffic situation.

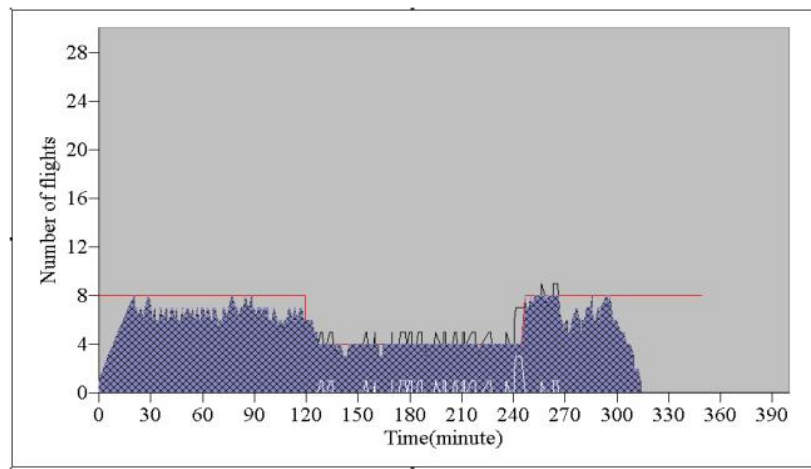

Fig. 9 ARTCC Introduces MIT and Reroute based on ARTCC and AOC
A comparison of the mean and standard deviation for 5 different strategies together is shown in Table 5. When strategy II is selected during the reduction in capacity there is an increase in the system delay time but a decrease in the system delay cost. Also strategy II can improve safety by translating the airborne delay into ground delay. When comparing strategy I, II and III, strategy III appears to be a better choice compared to strategies I and II; but the improvement in system delay time is less than $8 \%$ and in system delay cost it is less than $5 \%$. The greatest improvement in the system metrics occurs with strategies IV and V when compared to previous three strategies. And when comparing strategies IV and $\mathrm{V}$, strategy $\mathrm{V}$ shows better performance in system delay cost and total passengers delay time while strategy IV is better in improving system delay time.

Table 5. Comparison for 5 Different Strategies

\begin{tabular}{|l|l|l|l|l|}
\hline Strategies & $\begin{array}{l}\text { Delay } \\
\text { rate }\end{array}$ & $\begin{array}{l}\text { System } \\
\text { delay time }\end{array}$ & $\begin{array}{l}\text { System } \\
\text { delay cost }\end{array}$ & $\begin{array}{l}\text { Total PAX } \\
\text { delay time }\end{array}$ \\
\hline Strategy & & & $884,503 \pm$ & $322,459 \pm$ \\
I & $0.57 \pm 0.02$ & $2,281 \pm 154$ & 101,305 & 31,063 \\
\hline Strategy & & & $848,152 \pm$ & $334,086 \pm$ \\
II & $0.58 \pm 0.01$ & $2,367 \pm 155$ & 110,613 & 34,692 \\
\hline Strategy & & & $752,636 \pm$ & $304,794 \pm$ \\
\hline III & $0.57 \pm 0.01$ & $2,104 \pm 129$ & 91,852 & 31,749 \\
\hline Strategy & & & $331,836 \pm$ & $114,876 \pm$ \\
IV & $0.46 \pm 0.07$ & $796 \pm 200$ & 81,227 & 33,446 \\
\hline Strategy & & & $289,156 \pm$ & $99,521 \pm$ \\
V & $0.45 \pm 0.07$ & $885 \pm 178$ & 87,408 & 37,560 \\
\hline
\end{tabular}

\section{Conclusion}

Five strategies about alternative route selection based on cost and throughput are studied and analyzed in this paper. Comparing the performance metrics defined in our model, the strategy of ARTCC introduces MIT and Reroute based on ARTCC and AOCs is recommended here due to reduction in delay time and cost. The results of the analysis for each kind of strategy are:

- With no intervention undertaken to respond in advance to the weather, the average airborne delay time for each passed flight in the reduced capacity sector is 20.8 minutes. And, the maximum number of simultaneous airborne delay flights in this sector is 21 with a maximum 
airborne delay time of 60.6 minutes. The mean system flight delay time is 2,281 minutes (variance is 154 minutes) with mean system flight delay cost of 884,503 dollars (variance is 101,305 dollars).

- In presence of uncertainty in operations, maximum throughput is achieved without re-routing with a 5 minute MIT in the capacity reduced sector. However, though the average airborne delay time for each passed flight is reduced to 10.7 minutes, the maximum number of simultaneous airborne delay flights after MIT is as high as 22 and maximum airborne delay time is 52.6 minutes. The mean system flights delay time is 2,367 minutes (variance is 155 minutes) with mean system flights delay cost is 848,152 dollars (variance is 110,613 dollars).

- If AOCs do not cooperate with each other, the system-wide congestion problem cannot be solved efficiently. The average airborne delay time for each passed flight can be further reduced to 7.7 minutes. However, the number of maximum simultaneous airborne delayed flights is still as high as 18 with 44.2 minutes maximum airborne delay time. The mean system flights delay time is 2,104 minutes (variance is 129 minutes) with the mean system flights delay cost of 752,636 dollars (variance is 91,852 dollars).

- Following the rerouted flight suggestions from ATCSCC, the AOCs can solve both the congestion problems and the large spike problem efficiently. The average airborne delay time for each passed flight is reduced to 0.7 minutes, the maximum simultaneous airborne delay flights reduced to 9 with 22 minutes maximum airborne delay time. The average airborne delay time for each passed flight is reduced to 0.7 minutes, the maximum simultaneous airborne delay flights reduced to 9 with 22 minutes maximum airborne delay time. The mean system flights delay time is 885 minutes (variance is 178 minutes) with the mean system flights delay cost of 289,156 dollars (variance is 87,408 dollars)
- When a 5 minute MIT with $40 \%$ flights rerouted is provided by ARTCC based on based on LFRF, the optimum solution can be obtained. The average airborne delay time for the congested sector is 0.18 minute, the number of maximum simultaneous airborne delayed flight is 9 with 21.5 minutes maximum airborne delay time. The mean system flight delay time is 796 minutes (variance is 200 minutes) with the mean system flights delay cost is 331,836 dollars (variance is 81,227 dollars).

\section{References}

[1]H. Idris, A. Evans, R. Vivona, J. Krozel, and K. Bilimoria, 2006, "Field Observations of Interactions Between Traffic Flow Management and Airline Operations" in AIAA ATIO Conference, Wichita, Kansas, pp. 1-17, 2006.

[2] S. R. Wolfe, F. Y. Enomoto, P. A. Jarvis, and M. Sierhuis, 2007 "Comparing Route Selection Strategies in Collaborative Traffic Flow Management", in IEEE/WIC/ACM International Conference on Intelligent Agent Technology,IAT '07, pp. 59-62.

[3] Federal Aviation Administration, 18-Oct-2011, "Cololaborative Trajectory Options Program (CTOP) Interface Control Document (ICD) for the Traffic Flow Management System (TFMS)".

[4] K. Bilimoria, S. Banavar, C. Gano, S. Kapil, and G. Shon, 2001, "FACET: Future ATM Concepts Evaluation Tool", Air Traffic Control Quarterly, vol. 9, no. 1, pp. 1-20, 2001.

[5] D. N. Sweet, V. Manikonda, J. S. Aronson, K. Roth, and M. Blake, August 2002, "Fast-time simulation system for analysis of advanced air transportation concepts", Proceedings of the AIAA Modeling and Simulation Technologies Conference, pp. 5-8, 2002.

[6] C. Wanke, S. Zobell, and L. Song, 2005, "Probabilistic airspace congestion management", in AIAA 5 th Aviation, Technology, Integration, and Operations Conference(ATIO), pp. 1-15.

[7] K. Ramamoorthy, B. Boisvert, and G. Hunter, 2006, "A Real-Time Probabilistic Traffic Flow Management Evaluation Tool", in 25th Digital Avionics Systems Conference, 2006 IEEE/AIAA, pp. $1-13$. 
[8] G. Calderon-Meza and L. Sherry, 2011, "Adaptive agents in NAS-wide simulations: A casestudy of CTOP and SWIM", in Integrated Communications, Navigation and Surveilance Conference (ICNS), 2011, p. F6-1-F6-13.

[9] W. D. Kelton, 2003, R. P. Sadowski, and D. T. Sturrock, Simulation with Arena. McGraw-Hill Higher Education.

\section{Acknowledgement}

The authors would like to thank Dr. George Donohue, Mrs. Paula Lewis, Dr. John Shortle, Dr. Vivek Kumar, Dr. Terry Thapsan, Akshay Belle, Yimin Zhang, Zhenming Wang and Ashwin Samant for the review comments and suggestions.

\section{Appendix I. List of key parameters}

\begin{tabular}{|l|l|l|}
\hline Metric Name & Value Type & Sample Value \\
\hline Flights number & constant & 100 aircrafts \\
\hline Flights types & random variable & Connecting/non-connecting \\
\hline Aircraft types & random variable & Heavy/Large/Medium/Small \\
\hline Unit time airborne fuel cost & dynamic variable & $10000 / 6500 / 2500 / 1000 \$ /$ minutes \\
\hline Unit time GDP fuel cost & dynamic variable & $500 / 325 / 125 / 50 \$ /$ minutes \\
\hline Seat number & dynamic variable & $325 / 250 / 150 / 75$ \\
\hline Unit time passengers delay cost & constant & $60 \$ /$ minutes \\
\hline Unit time crew delay cost & dynamic variable & $6000 / 4500 / 3000 / 1500 \$ /$ minutes \\
\hline Load factor & random variable & Unif $(0.75,0.9)$ \\
\hline Sector passing time & random variable & Norm $(20,1.2)$, Norm $(22,1.5)$ \\
\hline Sector capacity resources & dynamic variable & $8 / 4 / 2$ \\
\hline Inter-arrival times & random variable & Norm $(3,0.5)$ \\
\hline Scheduled en-route time & Constant & 60 minutes \\
\hline Experiments times & Constant & 100 per strategy with fixed parameters \\
\hline
\end{tabular}

\section{Appendix II. ARTCC Introduces MIT and Reroute}

\begin{tabular}{|l|l|l|l|l|l|l|}
\hline $\begin{array}{l}\text { ARTCC introduces } \\
\text { MIT and Reroute }\end{array}$ & $\begin{array}{l}\mathbf{2 0 \%} \\
\text { reroute }\end{array}$ & $\begin{array}{l}\mathbf{2 0 \%} \\
\text { reroute }\end{array}$ & $\begin{array}{l}\mathbf{3 0 \%} \\
\text { reroute }\end{array}$ & $\begin{array}{l}\mathbf{4 0 \%} \\
\text { reroute }\end{array}$ & $\begin{array}{l}\mathbf{5 0 \%} \\
\text { reroute }\end{array}$ & $\begin{array}{l}\mathbf{6 0 \%} \\
\text { reroute }\end{array}$ \\
\hline Number of Fight & 100.00 & 100.00 & 100.00 & 100.00 & 100.00 & 100.00 \\
\hline On-time departure rate & 0.63 & 0.67 & 0.71 & 0.75 & 0.80 & 0.84 \\
\hline Delay rate & 0.57 & 0.56 & 0.53 & 0.46 & 0.40 & 0.39 \\
\hline Sector Delay time (minutes) & 1,825 & 1,383 & 998 & 796 & 870 & 1,206 \\
\hline Sector Delay cost $(\$)$ & 647,309 & 488,555 & 359,919 & 290,758 & 332,813 & 451,515 \\
\hline System Delay Time (minutes) & 1,880 & 1,447 & 1,078 & 910 & 1,006 & 1,345 \\
\hline System Delay Cost $(\$)$ & 667,927 & 512,148 & 389,482 & 331,836 & 381,280 & 500,931 \\
\hline Number of delayed passengers & 8,248 & 8,074 & 7,677 & 6,653 & 5,793 & 5,649 \\
\hline Total passenger delay time (minutes) & 262,279 & 200,278 & 145,034 & 114,876 & 125,075 & 175,227 \\
\hline
\end{tabular}




\section{Appendix III. Selection Based on VFRF}

\begin{tabular}{|l|l|l|l|l|l|l|}
\hline $\begin{array}{l}\text { ARTCC introduces MIT + Reroute } \\
\text { based on ARTCC and AOC }\end{array}$ & $\begin{array}{l}\mathbf{1 0 \%} \\
\text { reroute }\end{array}$ & $\begin{array}{l}\mathbf{2 0 \%} \\
\text { reroute }\end{array}$ & $\begin{array}{l}\mathbf{3 0 \%} \\
\text { reroute }\end{array}$ & $\begin{array}{l}\mathbf{4 0 \%} \\
\text { reroute }\end{array}$ & $\begin{array}{l}\mathbf{5 0 \%} \\
\text { reroute }\end{array}$ & $\begin{array}{l}\mathbf{6 0 \%} \\
\text { reroute }\end{array}$ \\
\hline Number of Fight & 100.00 & 100.00 & 100.00 & 100.00 & 100.00 & 100.00 \\
\hline On-time departure rate & 0.64 & 0.67 & 0.72 & 0.76 & 0.80 & 0.84 \\
\hline Delay rate & 0.57 & 0.56 & 0.52 & 0.44 & 0.42 & 0.40 \\
\hline Sector Delay time (minutes) & 1,742 & 1,310 & 968 & 771 & 915 & 1,314 \\
\hline Sector Delay cost (\$) & 565,576 & 430,080 & 335,524 & 343,738 & 466,623 & 662,298 \\
\hline System Delay Time & 1,799 & 1,375 & 1,054 & 895 & 1,049 & 1,449 \\
\hline System Delay Cost & 590,238 & 456,868 & 368,124 & 384,868 & 506,022 & 700,796 \\
\hline Number of delayed passengers & 8,228 & 7,882 & 7,462 & 6,774 & 6,605 & 6,622 \\
\hline Total passenger delay time (minutes) & 242,641 & 174,089 & 133,690 & 130,022 & 166,402 & 245,837 \\
\hline
\end{tabular}

\section{Appendix IV. Selection Based on LFRF}

\begin{tabular}{|l|l|l|l|l|l|l|}
\hline $\begin{array}{l}\text { ARTCC introduces MIT + Reroute } \\
\text { based on ARTCC and AOC }\end{array}$ & $\begin{array}{l}\mathbf{1 0 \%} \\
\text { reroute } \\
\text { reroute }\end{array}$ & $\begin{array}{l}\mathbf{3 0 \%} \\
\text { reroute }\end{array}$ & $\begin{array}{l}\mathbf{4 0 \%} \\
\text { reroute }\end{array}$ & $\begin{array}{l}\mathbf{5 0 \%} \\
\text { reroute }\end{array}$ & $\begin{array}{l}\mathbf{6 0 \%} \\
\text { reroute }\end{array}$ \\
\hline Number of Fight & 100.00 & 100.00 & 100.00 & 100.00 & 100.00 & 100.00 \\
\hline On-time departure rate & 0.63 & 0.67 & 0.72 & 0.76 & 0.80 & 0.84 \\
\hline Delay rate & 0.57 & 0.55 & 0.51 & 0.45 & 0.40 & 0.39 \\
\hline Sector Delay time (minutes) & 1,806 & 1,307 & 944 & 765 & 895 & 1,281 \\
\hline Sector Delay cost (\$) & 663,482 & 491,175 & 339,159 & 242,825 & 221,791 & 303,908 \\
\hline System Delay Time & 1,862 & 1,374 & 1,036 & 885 & 1,033 & 1,420 \\
\hline System Delay Cost & 682,276 & 513,685 & 372,412 & 289,156 & 279,831 & 365,301 \\
\hline Number of delayed passengers & 8,452 & 8,092 & 7,266 & 6,261 & 5,202 & 4,611 \\
\hline Total passenger delay time (minutes) & 273,096 & 198,737 & 138,184 & 99,521 & 94,899 & 122,848 \\
\hline
\end{tabular}

\section{Conference Identification}

\section{Integrated Communications Navigation and Surveillance (ICNS) Conference}

